\title{
Ciência, Conhecimentos ou Metaconhecimento?
}

\author{
Science, Knowledge or Meta-knowledge?
}

Doutorando Leandro Timotheo Muniz - PPGFIL UERJ

leandrotimotheo@gmail.com

ORCID: https://orcid.org/00000002-5852-0557

Data de recebimento: 05/06/2020

Data de aceite: 24/09/2020
Logo no início da pandemia da covid-19, Bruno Latour nos convidou a pensar em possibilidades para um mundo pós-pandemia, "imaginar gestos que barrem o retorno da produção pré-crise" (LATOUR, 2020), para que o mundo possa continuar a ser produtivo, porém, dentre outros problemas, ser menos poluído e menos desigual socialmente. Latour nos incentivou a buscar soluções ou imaginá-las partindo do princípio de que pode haver determinadas atividades, inclusive realizadas por nós próprios, que gostaríamos que fossem reorganizadas ou extintas, - pensando também nos processos produtivos envolvidos, nas demandas sobre essa produção e na poluição resultante desse processo. Como continuar produzindo e abastecendo os consumidores sem poluir ou poluindo menos? Como continuar a produzir e protegendo também as pessoas envolvidas nesses processos? Ou seja, há também a necessidade de que nossas respostas sejam afirmativas em relação à existência dos seres humanos no mundo e, não, uma saída que procure negar os problemas existentes no Planeta Terra, sobretudo os problemas da poluição, da fome, da uberização do trabalho e da violência. Em geral, para darmos conta desses problemas necessitaríamos viver em uma sociedade livre, plural e educada formalmente.

Responder adequadamente aos problemas apresentados por Latour é uma tarefa das mais difíceis, mas, a ciência, certamente nos dá condições para entender esses problemas reais e também os meios para que possamos combatê-los, e com isso talvez até consigamos melhorar o mundo em que vivemos. Além disso, em conjunto com outras áreas do conhecimento, a ciência ainda poderia fornecer fundamentos suficientes para pôr em prática as soluções viáveis, quem sabe, até tornando possível a convivência responsável entre os seres humanos e a natureza como um todo. Mas, como convencer as pessoas sobre a importância da ciência e do seu ensino? Como podemos imaginar um mundo pós-pandemia tendo à frente a ciência e a educação formal como base necessária para um mundo mais livre, plural e responsável? 
As perguntas feitas por Latour que tentaremos responder, pensando em função do reconhecimento da importância da ciência na pós-pandemia, são as seguintes.

Quais as atividades agora suspensas que você gostaria que não fossem retomadas? Que medidas você sugere para facilitar a transição para outras atividades daqueles trabalhadores, empregados ou empresários que não poderão mais continuar nas atividades que você está suprimindo? Quais as atividades agora suspensas que você gostaria que fossem ampliadas, retomadas ou mesmo criadas a partir do zero? Que medidas você sugere para ajudar os trabalhadores, empregados e empresários a adquirir as capacidades, os meios, as receitas e os instrumentos para retomar, desenvolver e criar esta atividade? (LATOUR, 2020).

Existem várias maneiras de se começar a responder a essas perguntas com ideias sobre o mundo pós-pandemia, poderíamos pensar em variados objetivos, abordar o assunto pragmaticamente por exemplo. $\mathrm{O}$ que não conseguimos é deixar de pensar no mundo que tínhamos antes da pandemia: poluição ambiental, desmatamento, genocídio de povos e culturas, violência contra a mulher e os pretos, principalmente no Brasil. Os problemas são muitos, incluindo aqueles que nem nos damos conta que existem. Vamos pensar em alguns para responder a Latour, mas, nossa intenção é a de que a importância do conhecimento, sobretudo o científico, seja o foco para não retornarmos aos modelos produtivos menos aceitáveis do mundo "pré-crise"; e pensar nesse "pós", no "após", no "depois" já pressupõe estarmos inseridos ou impregnados por um tipo de temporalidade, de um tempo presumido. Essa concepção de tempo produtivo presumido, nós talvez também tenhamos que pensar em modificar, pois pode estar muito influenciada pelo modelo anterior de produção, o qual muitas das vezes tem apenas como objetivo aumentar os lucros no menor tempo possível da produção sem se estar compromissado com a saúde dos trabalhadores ou com a natureza. Mas, que tempo seria esse? Quem teria a posse desse tempo? Como foi dimensionada sua duração? Qual o impacto da noção de tempo produtivo no mundo?

Olhando para os processos de datação mais adotados, veremos a Terra tendo algo em torno de quatro bilhões e meio de anos em um Universo que tem por volta de 13,7 bilhões de anos; anos esses com 365 dias e 6 horas. Mas, para quê isso? Por que precisamos estar dimensionando a passagem do tempo? E pensar isso em relação à ciência torna tudo mais complexo e possivelmente radical - ao buscarmos em nossa memória social o quanto custou em esforços pessoais e muitas renúncias emocionais - para o advento do que entendemos por ciência nos dias de hoje. A ciência é uma recém-nascida na História deste Planeta: a Terra. Cobrar de algo tão recente uma responsabilidade intransferível e apocalíptica parece sem sentido. Logicamente imaginando que não consideramos a tarefa da ciência como uma missão ou paraquedas salvacionista para todos os nossos problemas. Afinal de contas, quem exatamente reflete fundamentado exclusivamente em postulados e teorias científicas? Postados em mais uma encruzilhada da História, a humanidade parece estar perplexa, e nos indagamos sobre o que será feito da ciência depois que esse Mundo pandêmico "acabar"? Qualquer possibilidade de resposta minimamente fundamentada em postulados éticos levaria em conta de que é preciso o comprometimento com as coisas do mundo.

Parece nítido, pelos fatos observados mundo a fora, que a Natureza precisa urgentemente que a Humanidade utilize de seus conhecimentos e da fé na ciência como sustentabilidade do convívio entre todos, considerando os animais, as florestas, as geleiras, os desertos, enfim, todos os ecossistemas. Esse é o compromisso, mas, como convencer a todos os participantes humanos do Planeta dessa urgência? Somente a ciência, sozinha, e a tarefa poderá certamente não ser concretizada. Acreditando na ciência como um conhecimento sem o qual continuaremos incertos sobre pandemias e outros problemas similares no futuro imprevisível, mas, mesmo assim percebido. Então, indagamos: qual será a tarefa da ciência nesse mundo novo que se aproxima?

O Planeta Terra é inocente para tanta gente descerebrada. Anos e anos de pesquisas, teorias, hipóteses, 
verificações, testes, comprovações de hipóteses, descobertas e soluções para problemas diversificados. Sendo alguns desses problemas mais palpáveis e exemplificáveis. Já outros, estão há anos luz da compreensão da maioria dos seres humanos. Então, como apostar em algo que não conseguimos, em todas as ocasiões e circunstâncias, explicar convincentemente a qualquer plateia? Como defender as competências e habilidades singulares de que a ciência é a portadora? Mesmo que incompreensível para a maioria das pessoas, como defender que a ciência, é o caminho, é a seta e o alvo? Você investiria em algo que poderá não gerar retorno financeiro? Investiria em pessoas que podem não conseguir lhe explicar como e porque executam suas tarefas? Investiria o tempo da civilização em um conhecimento que poderá nunca acontecer ou ser pragmaticamente útil em algum dia?

Como alguém poderia expor a ciência ao mundo de uma maneira que seu discurso não só pudesse ser entendido, mas, igualmente tornar-se referência e orientação para as tomadas de decisões da própria civilização? Pessoas podem não entender uma hipótese científica ou uma ideologia política. Porém, dentro de uma estrutura cultural de valores, daquilo que se tem como bom ou ruim, como verdadeiro ou falso, correto ou errado, temos a possibilidade em tentar dar suporte para expor as bases ou os fundamentos de uma atividade pretendida, ou de uma utilidade institucional e, dentre outras coisas, também, poderíamos demonstrar com exemplos inclusive, os motivos de se dar importância ao discurso científico.

Em uma cultura como a nossa, - lembrando que o nosso mundo ideal, para darmos respostas adequadas a Latour, teria uma estrutura pluralista, que é justamente o que não temos na realidade social em que vivemos -, o discurso da ciência, para tornar-se, pós-pandemia, o orientador das ações vindouras, deve não só se afirmar discursivamente pelos trabalhos prestados ao longo de sua história, mas, inclusive, pelos valores intrínsecos à atividade de cientista, tudo isso auferido por sua estrutura ética e moral. Os seres humanos aprendem por exemplos e quase nunca por manuais; por isso, todos os exemplos das ações práticas dos envolvidos no combate à pandemia deverão ser a pedra filosofal do discurso da ciência para a posse valorativa das orientações políticas, sociais e econômicas sobre os fazeres e deveres da Humanidade no Planeta Terra pós-pandemia. Estamos utópicos demais, românticos demais - o mundo dos humanos nunca foi complacente assim quando o que está em jogo é o poder. O que fazer então?

Por que a ciência precisa expor seus valores para conquistar o discurso orientador da Humanidade? Porque as pessoas não vão entender os processos da ciência, as pessoas só entendem resultados, e somente quando os resultados lhes interessam por solucionarem problemas insolúveis para outras áreas do conhecimento ou para si próprios; o negacionismo é uma realidade inglória. Mas, sabemos que muitos dos seres humanos conseguem compartilhar o entendimento sobre valores. Talvez por isso, a exemplificação através dos valores da ciência possa ser capaz de influenciar e convencer a maioria da Humanidade, tanto sobre a eficácia da ciência quanto sobre como deve-se orientar os passos no caminho mais seguro descoberto pelas pesquisas científicas no mundo "pós-crise". O conhecimento tem de nascer dentro da pessoa, por ela própria, mas as condições oportunas e os incentivadores têm que estar presentes.

$\mathrm{Na}$ quarentena ficou nítido para boa parcela da população mundial de que podemos viver com menos em um mundo mais limpo e, para isso, basta darmos importância a todo um conjunto de processos e vivências diferentes do que fazíamos antes. A ciência é um dos conhecimentos mais aptos para ajudar nessa virada civilizatória. Parece que para isso o tempo produtivo também deverá ser repensado, pensemos no quanto o desenvolvimento de vacinas para combater a covid-19 nos mostra isso claramente, o tempo das etapas nas pesquisas não é controlável absolutamente, há testes, maturação, reflexão, novos testes, apresentação dos resultados, etapas que separam as ideias teóricas do resultado prático pretendido por todos, e isso, de forma geral, é entendido pelo grande público; - mesmo que esse entendimento se dê na maioria das vezes somente dessa forma utilitária e, às vezes nem dessa forma. Então, seria importante educar as populações para isso, para o entendimento de que o conhecimento leva tempo maturando até, e se for possível, alcançar alguma descoberta. Mas, antes de tudo, temos que, enquanto povos e Estados, investir em pesquisas e em pesquisadores para que esse momento da descoberta possa de fato vir a aparecer em nossas realidades. Talvez a ideia conceitual que temos da Ciência também tenha que ser repensada nesse processo de convencimento público sobre a sua necessidade e o seu ensino. 
Voltando às questões de Latour, que não são simples ou fáceis de responder, pois embora sejam evidentes os problemas com os quais convivemos, as respostas e soluções caminham invariavelmente pelas fronteiras entre o que pode ser efetivamente realizado e o que, por enquanto, seria apenas utopia; além de ser difícil pensar em soluções globais para problemas locais, por isso, pensamos fundamentalmente em nossos problemas locais que possam ter semelhanças com o que ocorre em outras regiões do planeta. Começa Latour perguntando: "Quais as atividades agora suspensas que você gostaria que não fossem retomadas? Descreva por que essa atividade lhe parece prejudicial, supérflua, perigosa ou sem sentido, e de que forma o seu desaparecimento ou substituição tornaria outras atividades que você prefere mais fáceis ou pertinentes" (LATOUR, 2020).

Para nós, as monoculturas em grandes áreas de plantio utilizando agrotóxicos e que desmatam áreas de conservação ambiental para aumentar a produção, seriam esses casos. Em seu lugar, deveríamos incentivar a produção sem a utilização de agrotóxicos, em unidades produtoras rurais familiares, respeitando os limites das áreas de conservação e a idade escolar das crianças e jovens envolvidos nos processos. Outro ponto importante seria a proteção às nações indígenas e quilombolas que vivem nas fronteiras entre as áreas produtivas e as reservas. O trabalho educativo público nessas regiões seria importantíssimo.

"Que medidas você sugere para facilitar a transição para outras atividades daqueles trabalhadores, empregados ou empresários que não poderão mais continuar nas atividades que você está suprimindo?” (LATOUR, 2020)

As medidas utilizadas seriam a redistribuição das terras, devolvendo para as áreas de reservas seus espaços tomados pela expansão dos grandes latifúndios, começando pelas ocupações ilegais e respeitando as leis; depois reflorestando essas áreas devastadas; as famílias de camponeses cadastrados receberiam seus lotes e formariam cooperativas incentivadas pelo Estado e supervisionadas, no caso do Brasil, pela Empresa Brasileira de Agropecuária (Embrapa), Fundação Nacional do Índio (Funai) e Movimento dos Trabalhadores Rurais Sem Terra (MST), além da sociedade civil e das Universidades Públicas. Os grandes empresários do setor agrícola continuariam com suas propriedades, porém, ao longo dos anos, leis sobre o tamanho das propriedades seriam regulamentadas e essas terras seriam compradas e redistribuídas pelo Estado a partir de acordos entre as partes que seriam amplamente discutidos na sociedade. Especialistas de várias áreas do conhecimento auxiliariam nessas tomadas de decisões, sobretudo os das Universidades e da Embrapa. O princípio moral aceito aqui seria o de que a terra e as riquezas produzidas com uso da terra devam ser tratadas como de interesse público, de todos os habitantes de um país ou do planeta e, sendo assim, grupos e classes de pessoas isoladas não poderiam decidir sozinhos sobre o quê, o como e o para quem produzir riquezas com a terra e, também, não poderiam decidir sozinhos sobre a criação das leis reguladoras da sua posse e de seus limites de posse.

\footnotetext{
Quais as atividades agora suspensas que você gostaria que fossem ampliadas, retomadas ou mesmo criadas a partir do zero? Descreva por que essa atividade lhe parece positiva e como ela torna outras atividades que você prefere mais fáceis, harmoniosas, pertinentes e ajuda a combater aquelas que você considera desfavoráveis" (LATOUR, 2020).
}

O setor de transportes de massa, táxis e cooperativas de transportes deveriam ser realmente concessões públicas e cooperativas de pessoas, pensando principalmente no Brasil, embora também estejamos pensando nos outros povos e realidades do mundo. Para isso, não só o Estado e seus órgãos competentes, mas, a sociedade civil e as Universidades deveriam através de projetos e respaldo estatal atuar na organização do sistema e em sua operacionalidade, principalmente quanto a poluições sonoras e atmosféricas causadas por essa atividade. O investimento em um transporte menos poluente e que fosse controlado pela população e não somente por empresas privadas seria igualmente interessante, até como mecanismo de controle dos preços e dos impostos, 
em que a transparência dos custos e investimentos no setor fosse evidente. Esse setor da economia emprega milhares de pessoas direta e indiretamente, e por ter tanta importância estratégica envolvida, deveria dar conta dos interesses de todos os envolvidos no processo. Por isso, parte dos lucros dessa atividade deveria ser investido em laboratórios universitários públicos para o desenvolvimento estratégico do setor.

"Que medidas você sugere para ajudar os trabalhadores, empregados e empresários a adquirir as capacidades, os meios, as receitas e os instrumentos para retomar, desenvolver e criar esta atividade?" (LATOUR, 2020).

A educação popular é o maior desafio nessa questão, pois precisaríamos reeducar os agentes desse setor e a população para o entendimento de que o transporte é público e não a propriedade particular de pessoas e grupos. Ou seja, seria uma revolução, acreditamos, em qualquer do mundo e no Brasil, pensar e reestruturar o setor de transportes públicos. Mas, acreditamos que com a educação popular, com laudos técnicos desenvolvidos por especialistas das Universidades Públicas, com a mídia em geral tornando esses dados e essas ideias também públicas, com ampla campanha social e acordos entre as partes envolvidas, isso poderia ser realizado. Existem questões importantíssimas nesse setor da economia que interessam a todos. Durante o período de quarentena, a falta de circulação dos carros, das motocicletas, dos ônibus e dos caminhões tornou as cidades mais silenciosas, além de melhorar a qualidade do ar respirado. Dentre outras questões, podemos pensar também, no tempo de locomoção no trânsito das grandes cidades, no preço desse serviço e no conforto oferecido aos usuários, por esses meios de transportes coletivos. Talvez, com a vontade política nascida nesse processo, poderíamos até pôr em prática a noção de um transporte público utilizando energia mais limpa, tratando ao público e seus funcionários com respeito e com preços justos.

Todas essas mudanças possíveis precisam estar fundamentadas na ideia de que o conhecimento, sobretudo o científico, é imprescindível para vivermos em um mundo livre, plural e responsável socioambientalmente. Para isso, a educação popular é o motor principal da mudança, pois sob todos os aspectos e em última instância estamos pensando em uma mudança de mentalidade, ou seja, em uma revolução no pensamento. A tarefa não é das mais fáceis, porém, não é impossível.

Como novo modelo paradigmático, podemos apresentar algumas dessas questões e atitudes como sendo o que seria feito nas práticas dos cientistas e dos pensadores das sociedades - enquanto pessoas dedicadas à vida na Terra e a sua sustentabilidade biológica e cultural - sem esquecermos o compromisso ético e moral assumido anteriormente, sem esse compromisso tudo passaria a ser somente uma luta no campo político e social, envolvendo possivelmente ondas de violência e injustiças. Logo, pensamos que para convencermos as pessoas de maneira geral sobre a importância da ciência no mundo "pós-crise", o conceito de ciência deveria ser "alargado", abrangendo outras áreas do conhecimento e integrando todas as áreas afins. Como exemplos, poderíamos pensar nos cursos de Filosofia e os de Ciências, que talvez, deveriam ser recriados como um curso de Filosofia Natural; as áreas tecnológicas poderiam ser integradas às ciências compondo múltiplas opções de formação para aqueles que desejam se dedicar às buscas do novo; a Economia também poderia estar integrada às outras áreas, especialmente à Ética e à Política. O esforço para termos a ciência em amplos espaços de decisões passa também pelo esforço em mudarmos os rumos do conhecimento, de seus processos de transmissão, do seu ensino e da própria estrutura das sociedades nas quais está inserida.

A tarefa não é simples, e ainda temos a responsabilidade global pós-pandemia em continuar a despoluição atmosférica, dos mares, rios e lagoas, e trocando os meios de transportes por outros menos poluentes e pensando também nas classes trabalhadoras e operárias que vivem dessas atividades mais poluentes e precárias. Essa atitude poderia vir em comunhão à diminuição do consumo de supérfluos e até a diminuição do turismo em áreas de alto impacto ecológico. Alguns equipamentos e produtos também podem, com o planejamento adequado, ser compartilhados socialmente ou repassados circunstancialmente em cadeias de reutilização. Talvez, o impedimento ao extrativismo e à mineração em áreas definidas como ecossistemas de conservação mundial ou em áreas de convivências étnicas, que poderiam ser consideradas também como áreas de conservação, com suas propostas apresentadas e discutidas amplamente nas sociedades e levando-se em conta o interesse de todos os envolvidos, tornassem possível resolvermos muitos conflitos e problemas socioambientais importantes. 
Alguns modelos de geração e distribuição de energia limpa e renovável poderiam ser na pós-pandemia mais do que incentivados, poderiam ser o modelo principal de toda a geração de energia no Planeta Terra. É no mínimo inadmissível que em países tropicais não se utilize a energia solar, em regiões costeiras não se utilize a energia eólica ou a das marés, e até algumas outras menos conhecidas formas de geração de energia sustentáveis; conseguimos pensar rapidamente nos exemplos do biodiesel, na piezoeletricidade, na energia por ondas de campos eletromagnéticos e a energia maremotriz; a energia hidráulica; o gás-natural; a biomassa; a eólica; a solar; a geotérmica; a marítima; o biogás; e outras pesquisas científicas podem nos revelar ainda mais fontes de geração de energia limpa e renovável em suas buscas.

A necessidade de energia é crescente, e poderia não mais ocorrer em detrimento da vida no Planeta Terra. Para que todo esse processo possa ser realizado de fato, o investimento estatal é imprescindível. O apoio financeiro privado também. Logo, mecanismos legais com orientação pacífica, humanística e ecológica, deveriam ser criados para que toda a riqueza do mundo pudesse ser aproveitada em conformidade com todos os interesses propostos. Pois, não há produção sem recursos, pessoas, investimentos, pesquisas, inovação, maturação, distribuição, tarifas, impostos, cooperação, ou seja, a realidade é complexa e plural, uma nova realidade teria que ser fundamentada nisso. As pesquisas pela vacina da covid-19 demonstram isso claramente.

Então, responderíamos a Latour que para esse mundo "pós-crise" viver, o mundo anterior tem que morrer, e que essa transformação deve ser feita de forma ética e responsável, tendo a todos os povos e classes igualitariamente tratados e ouvidos, sejam como criadores, pensadores, produtores, fornecedores ou consumidores, e buscando uma convivência entre todos em atividades que possam ser solidárias, sustentáveis, prazerosas ou ecológicas. Assim, a “Terra” será uma tarefa compartilhada por todos nós, por todos os povos e classes, e teremos que dar tempo ao tempo para que processos como esses se tornem realidade. Pois, daqui em diante nessa temática, todo pensar poderá ser utópico somente, posto estar imerso em realidades até agora vislumbradas, sonhadas e concebidas por pura necessidade teórica e exercício do pensamento criativo. Estamos diante de um limiar, de uma fronteira separando mentalidades, e ao que tudo nos parece, boa parte das tentativas em responder a Latour para criar o novo, ou recriar o antigo, serão respostas que levarão em consideração tudo isso que está envolvido em nossos desejos, em nossos sonhos e em nossas realidades locais e regionais que acabam tendo impacto global, influenciando a todos e a tudo na Terra. Pensamos que a maneira mais evidente em tornar essa transformação possível está ligada invariavelmente ao investimento na educação formal popular dos povos, sobretudo incentivando práticas científicas em laboratórios escolares desde a educação básica das pessoas em todo o Planeta Terra.

\section{Referências}

LATOUR, Bruno. Imaginar gestos que barrem o retorno da produção pré-crise. AOC-Media Domingo 29 mar 2020. DANOWSKI, Deborah; CASTRO, Eduardo Viveiros (Trad.). Parution Disponível em <https://n-1edicoes.org/008-1> Acesso em: 10/09/2020. 